\title{
La historización de los conceptos teológicos
}

José María Mardones,

Instituto Superior de Investigaciones Cientílicas,

Madrid.

Una de las insistencias que recorren los escritos teológicos de I. Ellacuría es la necesidad de utilizar los conceptos teológicos. Formulado libremente quiere decir que es necesario dar carne histórico-social a conceplos como pecado, gracia, salvación, cruz, Iglesia, reino de Dios, etc. Esta propuesta no es nueva. Si algo quiere ser la teología en cuanto inteligencia de la fe, es ser una reflexión de lo que significan los conceptos tcológicos en cada momento socio-cultural, una tarea permanente de actualización del sentido de lo que se confiesa que tiene que integrar un discernimiento de los signos de los tiempos.

La historia del pensarniento en general, y también del teológico en particular, nos enseffa que lo obvio es lo más fácil de pasar por alto. De esta manera ha sucedido que las preocupaciones teológicas por estar a la altura de las exigencias metodológicas y académicas de su tiempo, la han empujado a conceder una gran importancia al diálogo con esas instancias, pero a olvidar su uraducción a la realidad. Se ha llegado, así, a una teología que era más un ejercicio de discusión y diálogo con las tradiciones de la comunidad teológica y del pensamiento, que con la situación social, polílica, económica; más aún, a que los conceptos teológicos aparecieran intemporales, abstractos, válidos para todo tiempo y lugar, $y$, por ello, sin referencia a ninguna parte, o únicamente a un supuesto "hombre de hoy" en general. Era una teologia, inevitablemente con una historia y un contexto, pero que ofrecía escasa atención a la historia Las categorías y conceptos utilizados, más bien se presentaban deshistorizados, aunque prestasen atención a la historiografra.

Parece una aportación de la teología de la liberación la preocupación por llenar de contenido histórico concreto los conceptos teológicos. Un ejercicio arriesgado, que le ha ganado muchas reticencias, cuando no francos rechazos y denuncias, al mismo tiempo que el reconocimiento, por otra pare, de una creati- 
vidad y sensibilidad admirables.

I. Ellacuría ofrece reflexiones importantes sobre el tcma de la historización de los conceptos teológicos. Me parece neccesrio tenerlos en cuenta y examinar sus sugerencias al respecto. A mi modo de ver estamos ante una de esas cuestioncs que señalan todo un estilo de pensamiento teológico, corrector de una deficiencia y olvido de la teología predominante, y que caracterizan el quehacer de la tcología de la liberación, o, al menos, de algunos de sus representantes. El centrarme en este punto manifiesta una preferencia personal, pero quiere ser uambićn el reconocimiento a una aportación objetiva de I. Ellacuría.

Procederemos abordando, en primer lugar, las raíces bíblicas de este proceso de historización; en segundo lugar, veremos su justificación filosófica y, finalmente, consideraremos algunas de las aplicaciones o historizaciones concretas propuestas por Ellacuría para algunos conceptos teológicos.

\section{Historicidad de los hechos biblicos}

Ellacuría es consciente de que Hegel es el pensador que eleva a la historia al lugar de la más alta admiración (1990, I,334). Pero encuenta en la revelación biblica el ejercicio expreso de una sensibilidad que sitúa en la historia la verdad y el don de Dios (1990, I,334). Tanto el Antiguo como el Nuevo Testamento enmarcan la revclación y donación de Dios.

¿Qué consecuencias tiene este heche para la comprensión de Dios y para ti quehacer tcologico?

\subsection{La historia como lugar teofánico}

El Antiguo y el Nuevo Testamento no usan la historia para confirmar la razonabilidad de nuestra fe, sino con el objeto de probar en esta acción histórica quién y cómo era su Dios (1990, I,333). De esta manera la historia se convierte así en probación de Dios porque es en sí misma mostración de Dios, y sólo en la historia es captado Dios como es en relación al hombre y el hombre como es en relación con Dios" (1990, 1,333).

No se niega que Dios se manifiesta en y por medio de la naturaleza o en y por la interioridad del sujeto humano, sino que se privilegia la historia como lugar teofánico. Más aún, como tendremos ocasión de argumentar brevemente, Ellacuria entiende que "la historia engloba y supera tanto el ámbito de lo natural como el ámbito de lo subjecivo y personal, y en ese sentido, lejos de excluirlos, los enmarca y potencia" (1990, I,333s).

De aquí nace la convicción de que "sin la hiswria queda absolutamente reducido el ámbito de revelación y de donación de Dios; y al, contrario, con la historia queda, por un lado, abierto lo que la humanidad y con ella la realidad entera puede dar de sí y, por otro lado, y, en consecuencia, queda abierta la 
posibilidad de mostrarse lo que es Dios para el hombre y el hombre para Dios" (1990, I,334).

Para conocer al Dios judeo-cristiano hay que ver cómo acuía en la historia. En la experiencia y por la experiencia histórica se revela Dios a los israelitas y a los cristianos. Y al recorrer esta historia conjunta de Dios con los hombres nos encontramos con un dato sorprendente: Dios es experimentado como el liberador de todo un pueblo oprimido. Este es el artículo fundacional de la fe veterotestamentaria, que, de nuevo, nos indica cómo no se puede ver a Dios separado de la historia humana, sobre todo de la historia de los sufrimientos y opresiones y de las luchas y esperanzas por salir de esas situaciones de inhumanidad.

La revelación de Dios acontece, por tanto, entreverada en o con la historia humana de opresión y libcración. Ellacuría acuña una fórmula sintética para expresar esta revelación en la historia de los oprimidos y en sus luchas en pro de la liberación, que trala de recoger el dinamismo que esa misma revelación genera: "la teofanía nace de una teopraxia y remite a una nueva teopraxia" (1990, I,336). Es decir, en el Dios que actúa en la historia de una forma liberadora para los hombres oprimidos, descubrimos a Dios y se nos revela un Dios que engendra y sostiene la esperanza y el esfuerzo en pro de la liberación. Esta es la experiencia de éxodo. No se quiere decir a través de un relato lo que Dios quiere del hombre en la historia, sino que se nos comunica que "Dios se hace presente en la historia, aunque el relato que exprese esta presencia no sea criticamente histórico" (1990, 1,339).

En suma, la revelación de Dios acontece en la historia. Y esto quicre decir

a) que la revelación divina se reconoce en la liberación histórica concreta (por ejemplo del pueblo judío de la opresión de Egipto), b) que en esa "experiencia de contraste" Dios indica realmente su nombre salvador, liberador, y c) que esta manifestación de Dios dinamiza la misma realidad y pone en juego la existencia humana de los implicados en pro de la liberación.

\subsection{El Deus semper novus de la historia}

El Dios que se revela en la historia como liberador abre la historia hacia un futuro de fraternidad y justicia. Señala lo que Dios no quiere que continúe ni prosiga en la historia y abre la expectativa de otra situación que puede ser y está llamada a ser. La promesa nace como experiencia de que Dios mismo empuja en la historia hacia su liberación. La esperanza es la respuesta creyente a la visión de la historia abierta hacia un futuro de salvación. De esta manera, queda también abierto lo que la humanidad y con ella la realidad entera puede dar de sí.

Esta historia abierta a un futuro de liberación nos dice algo acerca de Dios que se manifiesta de esta manera. Es un Dios que qucda también abierto a la historia. Su revelación no acontece de una vez por todas, sino a lo largo de la 
historia. Como dirá Ignacio Ellacuría: "en la historia no puede darse Dios de una vez por todas como es el caso de la naturaleza, aun admitido el caso de una evolución creadora (Bergson) o de una creación evolvente (Zubiri); en la historia se cuenta con la posibilidad de una revelación y autodonación permanente, no sólo por parte de quién la recibe sino, lo que es más radical, por parte de quien la da" $(1990,1,334)$.

Dios es, así, alguien que no sólo esłá más allá, sino más adelante. Quiere decir esto, que aunque se nos haya revelado fundamental e irrebasablemente en el Hijo, sobre todo, quién es este Dios, el misterio de Dios continúa abierto. Dios es permanente novedad, Deus semper novus.

Esta apertura radical al futuro de la historia y de la revelación de Dios mismo al hombre está llena de consecuencias. En primer lugar, la humanidad y la realidad estrón abiertas. Esto significa que ninguna situación histớrica puede presentarse como el cierre o la clausura de la historia. En un momento en que ha cxistido la tenlación de declarar "el lin de la historia" (F. Fukuyama) ante el triunfo del sistema capibalista democrático somos conscientes del alcance crítico y revolucionario de esta característica de "la historicidad de la salvación cristiana". Sencillamente queda puesto de manifiesto su sesgo idolátrico; la oposición a un Dios y a una humanidad abiertas al futuro. Dicho a la inversa, el Dios de la liberación es un Dios que "obliga a los hombres a abrirse y a no quedarse cerrados a ninguna experiencia ya dada ni en ningún límite definido" (1990, 1,335).

En segundo lugar, la historia aparece como el lugar pleno de la transcendencia. Es decir el Deus semper novus, se manifiesta en la historia que es el campo de la novedad, de la creatividad, "pero un campo donde Dios sólo puede revelarse 'más' si se hace efectivamente 'más' historia, esto es, una historia mayor y mejor que lo que ha sido hasta este momento" (1990, I,334). Se comprende ahora mejor lo demoníaco que hay en declarar un cierre de la historia: se impide no sólo que el hombre y la humanidad sean más, sino que Dios se nos revele más y mejor. Se impide que Dios sea Dios como quiere y desea serlo para nosotros.

\section{El Dios que suscita historia}

Estamos viendo que el Dios de la historia biblica es un Dios que genera historia. Pero entenderiamos muy mal todo lo dicho hasta aqui si no comprendiéramos cómo acontece esta revelación y autodonación liberadora de Dios en la historia. No es una presencia liberadora al margen del hombre. No es una praxis liberadora sin los hombres. Expresado al modo acuftado por las discusiones teológicas: no hay dos historias, una sagrada y otra profana sino una única hisloria donde hay acciones en favor de Dios y del pueblo y hay acciones en contra del pueblo y de Dios. Dios "aparece así como el momento transcendente de una única praxis de salvación, aquel momento que rompe los límites de la 
acción humana y/o reconduce el sentido más profundo de esa acción. Esto no supone reducir a Dios a la historia, sino que supone, al contrario, elevar la historia a Dios, elevación sólo posible en cuanto antes ha descendido a ella el propio Yahve" (1990, I,338).

Así mismo esta praxis de salvación no debe quedar reducida a actuaciones puramente sagradas o culturales, como tampoco éticas o sólo políticas. "La unidad total de una sola historia de Dios en los hombres y de los hombres en Dios no permite la evasión a uno de los dos exiremos abstracios: sólo Dios o sólo el hombre'; pero tampoco permite quedarse en la dualidad acumulada de Dios y del hombre, sino que afirma la unidad dual de Dios en el hombre y del hombre en Dios. Este en juega una distinta función y tiene una distinta densidad cuando la acción es de Dios en el hombre y cuando la acción es del hombre en Dios, pero siempre es el mismo en. Y por eso, no es una praxis meramente política, ni meramente histórica, ni meramente ética, sino que es una praxis histórica transcendente, lo cual hace patente al Dios que se hace presente en la acción de la historia" (1990, I,340).

Hay una gran historia de Dios que engloba la historia como un todo y que no se reduce a la vida estrictamente religiosa, sino que incluye la denominada vida profana. Ellacuría dirá que la mentalidad popular latinoamericana se sitúa con naturalidad en esta concepción que no separa lo religioso de lo profano y ve la historia de la salvación transitando por todo el campo de la historia (1990, I,353).

\subsection{Cristo como culminación de la historia de la salvación}

Jesús es el nuevo Moisés. El proceso histórico de la salvación alcanza en Jesús un paso cualitativamente nuevo, es el mediador fundamental de la historia de Dios. No es esto una ruptura con respecto a la concepción veterotestamentaria, sino que la especificidad neotestamentaria es una determinación de la transcendencia histórica que ahora toma una concreción y una cierta definilividad.

Estamos ante una novedad superadora que sin embargo, reafirma la lógica de la historia de salvación veterotestamentaria. Posee el mismo propósito fundamental de la liberación y choca contra parecidas contradicciones, pero, aunque de un modo distinto al mosaico, mantiene la referencia constitutiva a lo historico. La praxis histórica de Jesús revela en él una nueva y definitiva presencia de Dios, la cual proporciona nuevas perspectivas y nuevas dimensiones. Explicar éstas equivale a la tarea teológica de reformular conceptos como nuevo pueblo de Dios, pecado, gracia, salvación, cruz, etc. Una empresa que justamente es la que caracteriza a la teología de la liberación frente a otros modelos teológicos (1975b, 613). 
Pero algo debe quedar ya claro. La estructura de la historia de salvación muestra que la experiencia decisiva que hay que tener, tanto hoy como ayer, es la de la presencia viva de Dios en la historia. Esta experiencia, hoy como ayer. suscita historia y moviliza en pro de la liberación de los hombres. Y una reПlexión sobre esta experiencia de fe, teología, debe tener siempre presente que su "ámbito de realidad" no es Dios sin más, sino Dios tal como se hace presente en la propia situación histórica $(1975 b, 630)$. Por consiguiente, el problema de la teologla sera "inquirir reflexionando, en un primer momento, sobre los signos en que se muestra y se esconde la presencia salvifica de Dios en un Jesús que continúa a lo largo de la historia haciéndose carne" (1975b, 630).

En esta primera y rápida referencia a las raíces biblicas de la historicidad de la salvación percibimos algo que va a caracterizar el modelo de la tcología de la liberación: la .referencia a la historia, entendida ésta no como puro recorrido por los hechos históricos con el proposito de entenderlos o interpretarlos correctamente, sino como "adecuación a lo que es la historia como proceso real y englobante de toda la realidad humana, personal y estructuralmente considerada" (1975b, 618). Al ser la historia de la salvación "la gran historia de Dios con los hombres", que abarca tanto lo que pudiera llamarse la historia sagrada como la historia profana, la teología tiene que estar atenta a discemir lo que Dios hace en la historia de los hombres, es decir, a percibir lo que Dios quiere que resulte de su constante autodonación a la humanidad. Esto no se puede lograr sin un lipo de reflexión teológica que, sin perder de vista el recurso de los datos histónicos, atienda primordialmente a la historia en cuanto proceso de realización y, en definitiva, en cuanto proceso de liberación. Se prescribe desde aquí una vuelta a la historia misma en cuanto totalidad estructural de lo real en su proceso unitario, leído como el lugar más rico de la presencia y de la donación de Dios (1975b, 618; 1990, I,371-72). Una tarea para coda teologia, que, sin embargo, hoy parece recordar con especial insistencia la teologia de la liberación.

Pero antes de hacer alguna referencia al modo concreto como efectúa la historización de las categorías teológicas el mismo I. Ellacuria, vamos a ver la justificación filosófica de esta tarea. Será como sacar a la luz presupuesios fundamentales de lo que hace la teología cuando se propone historizar sus conceptos.

\section{El significado de la realidad histórica para ta teologia}

Hay una serie de presupuestos en toda aclividad humana, como es concretamente el quehacer teológico, que conviene explicar. Se accede así a un nivel crílico y de autoconciencia de lo que se está haciendo y por qué se está haciendo. Ellacuría dedicó algunas reflexiones a estos presupuestos del método tcológico latinoamericano (1975a, 325-350; 1975b, 609-635) y en casi todos sus escritus teológicos y filosólicos hay abundantes sugerencias que pueden ser to- 
madas como reflexiones sobre los condicionamientos y presupuestos de un pensar crílico. Vamos a considerar aquellas que juzgamos más centrales y que, sobre todo, inciden en la historización de los conceptos teológicos.

\subsection{La estructura dinámica de la realidad}

Ellacuría prosigue una tesis fundamental de X. Zubiri: los dinamismos de la materia, de la vida, de la persona y de la sociedad, se hallan "subtendidos dinámicamente" los unos por los otros en constitutiva respectividad, y se hacen todos ellos presentes en la historia. Esto significa que "el mundo, la realidad en tanto que mundo, es constitutivamente histórica. El dinamismo histórico afecta a la realidad constituyéndola en tanto que realidad. La historia no es simplemente un acontecimiento que les pasa a unas pobres realidades, como les puede pasar la gravitación a las realidades matcriales. No: es algo que afecta precisamente al carácter de realidad en cuanto tal" (Zubini, 1989, 272). La consecuencia, sobre la que insistirá Ellacuría, es que la historia es precisamente el lugar de la imbricación entre realidad e inteligencia, entre hombre y mundo.

La historia aparece así para la filosolía como lo úlumo de la realidad. Si para la filosofía clásica el concepto de lo último en la realidad era el ente nalural, y para la filosofia modema la subjetividad, habriamos llegado actualmente a ver "la necesidad de ampliar aún más ese concepto de lo último, de modo que en él entre con plena vigencia la realidad de lo histórico" (1985, 52; 1990a, 42). La realidad histórica es, por tanto, cl verdadero objeto de li filosofía. En cuanto tal realidad histórica es la unidad más englobante y manifestativa de la realidad.

Pero, ¿qué es esta realidad histórica objeto último de los esfuerzos filosó[1$\operatorname{cos?~"Es~la~totalidad~de~la~realidad~tal~como~se~da~unitariamente~en~su~forma~}$ cualitativa más alta (...) el campo abierto de las máximas posibilidades de lo real (...) es el ámbito de lo histórico" (1990a, 43), comprendido como el lugar donde la realidad da de sí y se muestra en él. Dicho de ouro modo, es el ámbito de la presencia de las demás formas de realidad y de los demás dinamismos. Se comprende así que el último libro, inacabado, de I. Ellacuría se titulara Filosofía de la realidad histórica y quiera ser un análisis de las distintas estructuras y dinamismos que comprenden la realidad histórica (desde la materia hasta la sociedad humana), a la búsqueda de las estructuras fundamentales de toda posible actividad liberadora. Finalmente, se pregunta por lo específico del dinamismo histórico y responderá que se halla en la praxis (1990a, 591), un concepto enormemente abarcador que implica "la totalidad del proceso social en cuanto transformador de la realidad tanto natural como histórica" (1985, 57; 1990a, 593). ¿Qué consecuencias tiene esta comprensión de la realidad hisıórica para la teorla, en cuanto momento de la praxis, y más concretamente para el conocimiento tcológico? 


\subsection{La historización de la inteligencia}

En continuidad con lo anterior (y con los análisis del inteligir humano de Zubiri) se comprende que la inteligencia humana quede afectada por la historicidad. Es una inteligencia histórica. Y por ello hay que entender desde una inteligencia, que "inicial y fundamentalmente es una actividad biológica", hasta que su función diferenciativa es la de "aprehender la realidad y la de enfrentarse con ella". Una realidad que es últimamente histórica y, por consiguiente, el conocimiento humano de la misma tiene que tener un carácter necesariamente práxico.

Se deduce ya aquí, que "lo especílico y formal de la inteligencia es hacer que el hombre se enfrente consigo mismo y con las demás cosas, en tanto que cosas reales, que sólo por su esencial respectividad con el hombre pueden tener para éste uno u otro sentido" (1975b, 625). Se equivocan, por tanto, aquellas filosofías que ponen el acento primario de la inteligencia humana en la comprensión del ser o la captación del sentido. Estas filosofías son idealistas y en cuanto sirven de base a una reflexión teológica la desorientan.

Por el contrario, la filosofía que entiende la inteligencia humana como un enfrentarse con las cosas reales en tanto que reales, impulsará a una inteligencia que se tiene que hacer cargo de la realidad (dimensión cognoscitiva realista), que liene que cargar con la realidad (carácter élico de la inteligencia) y que tiene que encargarse de la realidad (dimensión práxica de la inteligencia) (1975b, 626). Una tcología basada en esta concepción de la inteligencia dará prioridad a la realidad sobre el sentido, a la captación de la realidad histórica en orden a su transformación y no al sentido entendido contemplativa y vivencialmente.

Pero no se agotan en lo que llevamos dicho las consecuencias del carácter esencialmente histórico de la inteligencia. La historicidad de la inteligencia le conduce a Ellacuría a señalar una serie de aspectos de particular importancia para el quehacer teológico y que han sido también objeto de atención de todas aquellas teologías influídas por la teoría crítica, la crítica de las ideologías, etc. (Mardones 1979).

Uno de los aspectos derivados de la historicidad de la inteligencia es el carácler siujado de todo conocimiento. Es decir, la actividad de la inteligencia humana está condicionada por el mundo histórico en el que se da. De aquí la necesidad de conocer o indagar las condiciones históricas concretas en las que se da un conocimiento, teoría, propuesta de interpretación teológica, etc. El desvelamiento de tales condiciones puede explicar muchas de las características de esa formulación. Esto es válido, por ejemplo, para entender las diferencias entre el modelo latinoamericano de teología de la liberación y el predominantemente europeo.

La función práxica del conocer humano indica que "viene de y va a la con- 
figuración de una determinada estructura social" (1975b, 628). Sin incurrir en determinismos estrechos, quiere decir este rasgo que la autonomía del conocimiento es un "momento cultural de una totalidad histórica socialmente condicionada por determinados intereses y, más en general, por determinadas fuerzas sociales" (1975b, 629). Nos damos cuenta que todo conocimiento humano "tiene así una estricta dimensión social no sólo por su origen, sino también por su desunación" (1975b, 628). Es necesario, por tanto, para no ser víctima de oscuras ideologizaciones, efectuar una hermenéutica desveladora de los orígenes sociales y de las destinaciones saciales de todo conocimiento. Esta sugerencia es particularmente importante para el discurso teológico: ser consciente de su carácter social y de las funciones sociales que está llamado a realizar. De otra manera se condena a ser ciego socialmente, o, lo que es peor, a ser manipulado para fines diversos de los que dice seguir.

La referencia a la realidad, que estamos viendo posee la inteligencia, indica tambiên el carácler poiético estricto que tiene el conocimiento. La actividad y dinamicidad de la inteligencia no puede ser entendida de un modo intencional e idealista; tiende a objetivarse en realidades exteriores, más allá de la interioridad y de la intencionalidad subjetiva. Este rasgo es particularmente importante para la teología "que se relaciona con una fe, que pretende ser la vida misma de los hombres" (1975b, 629). La leologia, en cuanto encarna un momento activo de la inteligencia, quiere ver objetivado lo que expresa. Hay un impulso a la transformación de la realidad personal, social, en el discurso teológico. Olvidar esto es no hacer justicia a esta referencia a la realidad de todo conocimiento.

\subsection{La realidad histórica latinoamericana y la teología}

Dado que todo ejercicio del conocimiento, en este caso teológico, se efectúa siempre desde una situación, es conveniente tener claro ese ámbito de actividad. Para la teología latinoamericana es la situación, aquí y ahora, de Latinoamérica. El ceólogo debe preguntarse sobre los signos en que se muestra y se esconde la presencia salvífica de Dios en la realidad y en el hombre latinoamericano en la actual situación.

Ellacuría cree que para ello hay que atender "a la realidad de esa fe a través de una atención aguda y crítica a la religiosidad popular", y evitar caer en el elitismo que amenaza al teólogo por el doble flanco de la tentación académica (obtener reconocimiento entre las élites académicas) y por el de la significatividad política (ser reconocido por las élites revolucionarias) (1975b, 630-31).

La teología liene un doble carácter histórico: versa sobre la presencia de Dios en la propia situación hiśórica y es histórica como conocimiento situado. De aquí, si cabe, que deba extremar su sensibilidad para poder responder al para qué y al para quién de la teología, "que se compendia en la pregunta de a quién sirve lo que hacemos y para qué de hecho sirve lo que hacemos" (1975b, 631). 
Ignacio Ellacurfa insistirá en el de hecho a quién está sirviendo la transmisión y el contenido de esa transmisión, lo que de nuevo lleva a cuestionarse, circular e inevitablemente, por las realidades estructurales socio-históricas desde las que se hace teología y para las que se hace teologia. Este pensamiento teológico crítico y autocrítico posee, según Ellacuría, "una hermenéutica real e histórica".

La atención realista y no engañada al para qué y al para quién de la teología conduce a ésta a una atención crítica al lenguaje que usa y cómo lo usa, a sus posibles funciones veladoras, enmascaradoras e ideológicas. $Y$ lleva al difícil y permanente problema de la mediaciones.

El terna de las mediaciones ya es de por sí un amplio y espinoso problema Basta decir en este contexto de la historización de las categorias teológicas que sin él no se hace justicia a esta historización. Volveriamos, tras toda la argumenLación del carácter práxico y transformador de la realidad concreta a que se orienta el conocimiento humano, a detenemos a la puerta de salida del idealismo. Si se quiere interpretar y transformar el mundo cristianamente, se tiene que reflexionar sobre el modo concreto de hacerlo. Claro que aquí no está sola la teología y, quiza, deba elegir entre las propuestas que surgen desde otras ciencias. Ellacuría, que no hurtó el cuerpo a este ejercicio en la difícil y conflictiva salida política de su país, El Salvador, nos llama la atención sobre el carácter tenso y aproximativo de toda mediación. De aquí la necesidad de no absolutizar los medios. Se incurre en la idolatría. Y esto lo mismo cuando se recurre a una tcoría que a un sistema. El se defícnderấ y defenderá a la teología de la liberación de la acusación de la marxistización, de haber absolutizado el marxismo como teoría interpretadora mediadora, aunque sostendrá lo adecuado y necesario de su uso crítico, como de cualquier otro instrumento teórico relevante (1975b, 634). La llamada de atención es muy pertinente cuando, en un contexto muy diferente al de hace dos décadas, no es el marxismo la ideología más atractiva, sino las diversas versiones del capilalismo. Hoy el peligro de "mediación ambigua" no corre tanto por los lindes del marxismo, cuanto de un neoconservadurismo que, incluso, ofrece sus versiones teológicas de afinidad con el sistema dominante. Se cae así en una absolutización del sistema capitalista predominante, que, como muy bien señala Ellacuría, es una idolatria (Mardones 1991).

\section{Tres ejemplos de historización de conceptos teológicus}

Quisiera ejemplificar brevemente el trabajo concreto de historización de las categorias teológicas efectuadas por Ellacuría en tres conceptos: el reino de Dios, la Iglesia y el crucificado. Veremos cómo la sensibilidad teológica y de captación de la realidad se conjuntan para hacer propuestas arriesgadas, provocativas y profundamente evangélicas. Al mismo tiempo abordamos, desde lo más general a lo más particular, tres de las traducciones históricas más llamativas y originales de I. Ellacuría. 


\subsection{El reino de Dios o la utopía cristiana}

Historizar significa, como hemos visto, no contar la historia de un concepto, sino "ponerlo en relación con la historia" (1990, II,128). ¿Qué le ocurre a un concepto tan central como el de reino de Dios cuando lo tratamos de poner en relación con la historia?

La respuesta es que deviene la utopia $(1990,1,394)$. La utopía cristiana es la historización del reino de Dios. No hay otra forma de dar cuerpo histórico al concepto del reino de Dios sino es a través de una utopla. Pero Ellacuría nos harâ algunas precisiones. Hay una utopia cristiana general e indefinida que apunta a un futuro universal de fraternidad, justicia y felicidad cuya culminación es escatológica. Para operativizar esta utopia se requiere hacerla utopía concreta. Es la forma de historizar el reino de Dios tanto en el corazón del hombre como en las estructuras $(1990,1,395)$.

El ejercicio concreto de la utopía cristiana lo llama Ellacuria profetismo. "Se entiende aqui por profetismo la contrastación crítica del anuncio de la plenitud del reino de Dios con una situación histórica determinada" (1990, I,396). Todo un ejercicio de discemimiento de los signos de los tiempos y de dialéctica entre los límites históricos y su dinamismo y esa plenitud transcendente que llamamos reino de Dios.

Se comprenderá que no podemos más que insinuar las líneas de este trabajo de profetismo cristiano que comporta, por una parte, la contrastación críticonegativa con lo que no debe de continuar, leído desde la situación de Latinoamérica, y lo que ya sería posible empezar a realizar. Podríamos decir que sintetza, en conjunto, lodo el esfuerzo de la teología latinoamericana de la liberación, en cuanto es una teología no parcial, sino total o del reino de Dios. Ellacuria, con todo, ha hecho el esfuerzo de sintetizar las líneas maestras de tal utopia concreta latinoamericana. Lleva consigo una crítica del orden internacional en el que se inserta la realidad latinoamericana, concretamente del sistema del capitalismo democrático y de la misma Iglesia institucional (1990, I,399-409). Este profeusmo de denuncia y utopía propone "un proyecto global universalizable" que prioriza la justicia sobre la libertad, y se concreta, al mirar la realidad desde las mayoría populares, en una versión económico-cultural que va a denominar "una civilización de la pobreza" (1990, I,425). Se trataría de impulsar una civilización del trabajo, que sustituya a la civilización dominante del capital. "El objetivo utópico no es que todos tengan mucho por la vía de la apropiación privada y exclusivista, sino que todos tengan lo necesario y quede abiento a todos el uso y disfrute no acaparador y exclusivista de lo que es primariamente común" (1990, I,429). Por esta vía llega Ellacuría a discernir que, de los dos ordenamientos económicos hoy disponibles, ve al ideal socialista más cercano en lo económico a las exigencias utópicas del reino, sin por ello bajar la guardia de la crílica en ningún momento (1990b, 78s;1990, I,430s). Más allá de las 
mediaciones económicas que se puedan adoptar, lo que le parece claro y fuera de discusión es que "la civilización del trabajo y de la pobreza debe de sustiuir a la civilización del capital y de la riqueza" (1990, I,431).

Este intento de historizar el reino de Dios equivale a la propuesta de actualizar —en el sentido zubiriano de dar realidad actual - a la teología desde Latinoanérica. Nos queda así claro, de una forma global, el talante que anima a una teología preocupada por "categorizar interpretativa y prácticamente lo transcendente" desde la interpelación del Espíritu en la historia vivida desde Lalinoamérica.

\subsection{La Iglesia, sacramento histórico de salvación}

El concilio Vaticano II presentó a la Iglesia como sacramento de la salvación de Dios y de la unidad de todo el género humano $(L . G ., 1,48)$. Se puede leer ahí ya el intento de presentar una Iglesia como serial o símbolo significativo de la salvación. Es decir, se apunta a la realidad histónica en la que se tiene que visibilizar el símbolo (sacramento). Justamente esto es lo que subraya fuertemente Ellacuria cuando denomina a la Iglesia "sacramento histórico de salvación" (1990, II,128s). Dado que "una concepción histórica de salvación no puede teorizar abstractamente sobre lo que es la salvación", hay que partir de hechos y llevar a hechos históricos. En resumen, la Iglesia así concebida debe avanzar hacia una profunda "conversión de la Iglesia al reino de Dios, para anunciarlo y realizarlo en la historia" (1984).

Un modo de actualizar esta conversión de la Iglesia al reino de Dios pasa por incorporizar la historia material de los hombres $(1990$, II,139). Equivale a hacer de la sacramentalidad de la Iglesia no un culto, sino una asunción de un proyecto de liberación para las grandes mayoría populares. La liberación viene a ser así "la forma histórica de salvación", o, dicho de otro modo, la Iglesia realiza su sacramentalidad histórica salvífica liberando (1990, II, 134.136). Sin duda, esto lo realizara la Iglesia como fermento, colaborando a la utopía profética de una nueva humanidad mediada a través del avance hacia un nuevo orden internacional de la civilización del trabajo y la pobreza. Y todavía más concretamente, haciéndose una "Iglesia de los pobres" (1990, II,144s.). Entendiendo por "pobre" un concepto histórico-dialéctico, por consiguiente no absoluto, pegado a la realidad socio-histórica, y, al mismo tiempo, abierto al amor predilecto de Dios a ellos $(1990$, II,149).

La consecuencia más grave para la Iglesia de esta historificación de la sacramentalidad es que se aclara el "lugar social" de la Iglesia, que es el de "las inmensas mayorías desposeídas" (1990b, 156).

\section{El pueblo crucificado}

Un paso más en esta historificación de las categorias teológicas realiza Ella-

Digitalizado por Biblioteca "P. Florentino Idoate, S.J."

Universidad Centroamericana José Simeón Cañas 
curía cuando propone dar nombre concreto a la Iglesia de los pobres. Veíamos que son las grandes mayorías populares de nuesuro mundo. Pero delrás de este eufemismo se esconden los pobres de la tierra. Las grandes masas desposeídas de lo necesario para llevar una vida digna, es decir, para ser personas y poder ser creyentes, como ya supo Tomás de Aquino. Son las masas oprimidas de nuestro mundo actual, que son la mayoría de la humanidad (1990, II,189;1990b, 46).

Ellacuría da un giro sorprendente a la denominación cuando se pregunta por el significado de esta realidad histórica para la historia de la salvación. Ve en ellos "la continuación histórica de la vida y de la muerte de Jesús" (1990, II,201). Es decir, la encarnación histórica hoy del siervo de Yahvé, del crucificado, son estas mayorías oprimidas de la humanidad. La Iglesia de Jesús, el crucificado, se convierte así en la Iglesia de los pobres, es decir, del pucblo crucificado. Entendiendo por "pueblo crucilicado aquella colectividad que, siendo la mayoría de la humanidad, debe su siuación de crucifixión a un ordenamiento social promovido y sostenido por una minoría que ejerce su dominio en función de un conjunto de factores, los cuales como tal conjunto y dada su concreta efectividad histórica, deben esumarse como pecado" (1990, II,201).

No tiene nada de extraño que tras esta historificación de la soteriologia, que descubre el lugar histórico actual en donde y como se realiza hoy lo que fue la vida y la muerte de Jesús, volvamos a encontramos, de nuevo, inmersos en una tarea liberadora. Pero no es pequeño el correctivo introducido en la soteriología al uso: se desplaza el acento desde la moderna insistencia en individualizar la existencia humana, que termina siendo una insistencia teológica en la salvación individual, hacia la dimensión colectiva donde hoy se juega primariamente tanto la salvación como la perdición (1990, II,202). Este es el dato primario al que se suele cerrar los ojos y acaba siendo invisible de tan evidente. Una soteriología que no constate este dato desenfoca la realidad. Termina no viendo realmente al crucificado.

Tras esta constatación e interpretación debe venir el enfoque soteriológico. Porque no se trata de "magnificar salvíficamente el mero hecho de la crucifixión del pueblo, como si el hecho bruto de ser crucificado aportara sin más la resurección y la vida. Hay que iluminar esta crucifixión desde lo que fue la muere de Jesús para ver su alcance salvífico y el modo cristiano de esa salvación" (1990, II,203-4). Si el pueblo crucificado es la víctima del pecado del mundo, y también quien aportará la salvación al mundo, el modo deberá ser objeto de determinación histórica cambiante, aproximativa, que no excluye ni la organización política ni de cualquier otro género. Pero se tendrá siempre en cuenta que cualquier objetivación histórica queda sometida, sobrepasada y desbordada por la salvación de Jesucristo a la que apunta y quiere realizar (1990, II,214). 


\section{Conclusión}

He pretendido repasar, al hilo de los artículos fundamentales de I. Ellacuría, un aspecto de particular importancia para la teología: su historicidad. La necesidad que tiene toda teología de preguntarse y responder por dónde pasa hoy la salvación de Dios para nosotros. Ellacuría trató de seffalar dónde se escondía el dedo de Dios. Un ejercicio intelectual y de fe arriesgado. Difícil intelectualmente porque está exigiendo del teólogo finura a la hora de leer la realidad de los signos de los tiempos. Ejercicio de fe, porque, consciente de que la realidad loda está grávida de Dios, se atreve a señalar al misterio entre las brumas de la ambigüedad de la historia. Tarea peligrosa, porque apuntar por dónde hoy se transparenta la presencia ausente del crucificado en la realidad latinoamericana, y concretamente de El Salvador, es el desafío que se puede pagar con la muerte.

Con cl testimonio de su vida, no sólo de su empeño intelectual, pagó Ignacio Ellacuría. Por más discutibles que sean sus historificaciones teológicas llevan la seriedad del martirio. Ello no basta para concederles la verdad y la objetividad, cosa que él mismo estaba dispuesto a poner en tela de juicio ante el asomo de la primera objección con peso, pero sí le concede veracidad a su empresa. Y le proporciona autoridad a su método, a su modo de vivir la fe y el oficio teológico.

\section{Obras citadas}

I. Ellacuría

(1975a). "Tesis sobre la posibilidad, necesidad y sentido de una teología latinoamericana", en Teología y mundo contemporáneo (Homenaje a K.Rahner), Cristiandad Madrid.

(1975b). "Hacia una fundamentación filosófica del mélodo teológico latinoamericano", en AAVV. Liberación y cautiverio. Debate en rorno al método de la teología en America Latina, México.

(1984), Conversión de la iglesio al reino de Dios. Para anunciarlo y realizarlo en la historia, Sal Terrae, Santander.

(1985), "Función liberadora de la filosofía", ECA, 435-36, pág. 45-64.

(1990a), Filosofla de la realidad histórica, UCA, San Salvador.

(1990b), I. Ellacurí, Téblogo márir por la liberación del pueblo, Nueva Ulopia, Madrid.

(1990, I), Mysteriwn Liberationis. Conceptos fundanentales de la reologla de la Liberacibn, vol I, Trotte, Madrid (Contiene los arrículos de I. Ellacurfa: "Historicidad de la salvación cristiana"; Utopía y profetismo).

(1990,II), Mysterium Liberationis. Conceptos fundanentales de la teologla de la Liberación, vol II, Trolta, Madrid (Contiene los artículos de I. Ellacuría: "La Iglesia de los pobres sacramento histórico de liberación"; "El pueblo ctucificado").

J. M. Mardones

(1979) Teología e ideologia, Univ. de Deusto, Bibao. 
(1991). Capitalismo y religión. Lo religión polttica neoconservadora, Sal Terrae, Santander.

\section{Zubiri}

(1989), Estruetura dinámica de la realidad, Alianza, Madrid. 